\title{
Aubert, A.; Flecha, A.; Garcia, C., Flecha, R., Racionero, S. (2008) Aprendizaje dialógico en la Sociedad de la Información. Barcelona: Hipatia, pp.: 255.
}

La necesidad de basar las teorías educativas en autores y autoras de referencia en la comunidad científica internacional y en investigaciones de relevancia se hace cada vez más necesario si queremos superar la actual situación de fracaso escolar que viven nuestros centros educativos en nuestro país. Tal como plantean las autoras y autor, es necesario acabar con el fundamentalismo o actitud de resistencia ante nuevas explicaciones que permiten entender mejor cómo se aprende en cada momento.

Los resultados de los dos últimos informes PISA (2009 y 2006) nos han alertado de la grave situación educativa en la que nos encontramos. Aquel alumnado más perjudicado es el que más riesgo tiene de sufrir exclusión social: minorías étnicas, inmigrantes, con ingresos socioeconómicos bajos o con familias sin estudios académicos entre otros. Países como Finlandia, que ha obtenido las mejores puntuaciones en estas dos últimas evaluaciones, muestra como sí es posible conseguir el éxito educativo de todo el alumnado.

Siguiendo esta línea, el libro que presentamos, está basado en la investigación dirigida por el autor y autoras del libro. La mayor investigación sobre educación escolar y de mayor rango que se ha realizado hasta ahora en los programas marco de investigación de la Unión Europea: INCLUD-ED: Strategies for inclusion and social cohesion in Europe from Education.

La propuesta de aprendizaje dialógico desarrollada en dos grandes partes del libro nos ofrece un exhaustivo análisis de los autores/as y teorías que fundamentan la concepción de aprendizaje dialógico y los siete principios en los que se basa éste (diálogo igualitario, inteligencia cultural, transformación, dimensión instrumental, creación de sentido, solidaridad e igualdad de diferencias).

El mismo empeño que se muestra en analizar las teorías de los autores más relevantes en ciencias sociales con aportaciones al aprendizaje dialógico, también se muestra para desmentir interpretaciones sin base científica de autores de la relevancia de Vygotsky. Un autor que ha sido utilizado para justificar las prácticas de adaptación a la diversidad, cuando, tal y como se muestra en el libro, en ninguna de 
las obras del autor se hace referencia a la idea que para mejorar el aprendizaje de niños y niñas lo mejor sea adaptar. Todo lo contrario su propuesta parte en todos los casos de la transformación del entorno de esos niños y niñas para conseguir unos resultados exitosos.

La rigurosidad con la que se muestra el análisis de los diferentes autores y los ejemplos prácticos con los que se relaciona la teoría, junto con una gran dosis de ilusión, nos ofrece una ocasión única para conseguir una educación que sí sea capaz de dar respuesta a los retos que plantea la sociedad informacional y no excluya a ningún colectivo.

Noemí Martín Casabona, professora del Departament de Pedagogia de la Universitat Rovira i Virgili. 